\title{
O PAPEL INTERPRETATIVO E INTEGRATIVO DOS TRATADOS INTERNACIONAIS SOBRE DIREITOS HUMANOS PERANTE A CONSTITUIÇÃO FEDERAL
}

\author{
João Fabrício Dantas Júnior ${ }^{1}$
}

Recebido em: 01/12/2018

Aprovado em: 25/02/2019

\begin{abstract}
RESUMO
A Constituição Federal de 1988 ordena, inicial e ulteriormente, pelos parágrafos $2^{\circ}$ e $3^{\circ}$ de seu Artigo $5^{\circ}$, que princípios e regras presentes em outros documentos tenham importante e decisivo papel em integrar, modificar tacitamente e ainda dirigir interpretações do texto constitucional quanto do manuseio concreto dos direitos fundamentais presentes no documento inaugurador do Ordenamento Jurídico brasileiro. Entender essa ordem do texto constitucional é entender mecanismos necessários interpretativos que abrem o sistema jurídico brasileiro para a construção de uma rede protetiva que pretende ser global e perfeita, e que, por técnica jurídica, consagra a posição do titular do poder político brasileiro: o povo. Uma integração política que ainda caminha a passos lentos, que objetivamente produziu apenas um único documento, mas que poderia fazer valer normas principiológicas a influenciar interpretações e concretizações de novos ou mais fortes direitos onde o legislador ordinário não agiu a emendar o próprio texto constitucional ou, pelo menos, a garantir-lhe infraconstitucionalmente. O Ordenamento Jurídico Brasileiro não se apequena a novos pensamentos, direitos e normas internacionais quando esta integração é por ele mesmo prevista, incentivada e ordenada, muito menos quando as linhas valorativas já são previstas na própria Constituição Federal de 5 de Outubro de 1988. Se não falta possibilidade jurídica, talvez não possamos dizer o mesmo do interesse, sensibilidade e perspicácia legislativa e jurisdicional quando do trato e pesquisas sobre documentos internacionais que colorem ainda mais o texto seco constitucional.
\end{abstract}

Palavras-Chave: Direitos Fundamentais. Dignidade da Pessoa Humana. Tratados.

\section{INTRODUÇÃO}

\footnotetext{
${ }^{1}$ Mestrando em Direito Constitucional pela Universidade Federal do Rio Grande do Norte - UFRN. Pósgraduado em Direito do Estado pela Universidade Anhanguera - UNIDERP. Advogado.
} 
A Constituição Federal de 1988 reservou papel de destaque aos tratados internacionais de direitos humanos. Direitos dessa qualidade, positivados no ordenamento jurídico brasileiro (direitos fundamentais), possuem um regime jurídico ímpar dentre todos os outros temas presentes no texto constitucional: eles demandam elasticidade documental e interpretação ampliativa. Observado isso, por escolha política dos constituintes de 5 de Outubro de 1988 e ainda por previsão constitucional cronologicamente mais moderna, aquelas espécies de tratados (em verdade, que se diferenciam por suas espécies de temas) podem trazer novos dispositivos de igual valor positivo, capazes de revogar implicitamente alguma regra que restrinja um direito fundamental já existente ou ainda trazer novos direitos humanos ao caráter legal (strictu sensu) de direito fundamental junto ao ordenamento jurídico brasileiro.

O papel dos Tratados Internacionais sobre Direitos Humanos, no alcance interpretativo que a Constituição Federal de 1988 pode ter, apresenta-nos como aqueles documentos foram trazidos ao Ordenamento Jurídico Brasileiro. Quando o texto constitucional faz, de posse das prerrogativas positivas que acompanham um poder constituinte e por falta de amarras legais a permitir inaugurar o Ordenamento Jurídico assim, ou ainda por autorização e adequação que permitam alterar o texto para, só então a partir deste momento posterior, dar a roupagem que politicamente o povo, por seus representantes, ache mais adequada a aquelas espécies normativas, está ele a se reinventar, a reinventar o Ordenamento, num exercício autopoiético que apenas nesse específico assunto é possível observar, conforme a composição atual da Constituição Federal.

Os direitos fundamentais presentes na Constituição Federal, assim visto, compõem o único tema presente naquele texto que demanda decisivamente uma leitura legal paralela ao próprio texto constitucional, pois não haverá ressalvas no texto seco sobre quais tratados internacionais vieram a tratar mais protetiva e/ou mais amplamente um determinado tema alinhado a um direito fundamental presente no texto constitucional. Não haverá no texto seco ressalvas sobre quais tratados internacionais sobre direitos humanos foram recepcionados seguindo-se o quórum de emenda constitucional. Sim, o próprio texto constitucional, erigindo-se às possibilidades permitidas pelas prerrogativas juridicamente possíveis aos poderes constituintes originários, se fez permitir plural, nos dando mais obrigações acadêmico-científicas quando do exercício hermenêutico acerca dos direitos fundamentais presentes na Constituição, que faz aflorar necessitado viés investigativo quando se debruça sobre o texto.

É honesto afirmar que, desde 5 de Outubro de 1988, ou, mais especificamente, desde a promulgação da Emenda Constitucional 45 promulgada em 30 de Dezembro de 2004, 
reconfigurou-se como os tratados internacionais sobre direitos humanos poderiam influenciar o rol dessa espécie de direito já presentes junto ao texto original da Constituição Federal, pois acrescentou ao Artigo $5^{\circ}$ os parágrafos $3^{\circ}$ e $4^{\circ}$. Apenas um único documento desta qualidade fora aprovado pelo procedimento imposto pela referida emenda: a Convenção sobre os Direitos da Pessoa com Deficiência ${ }^{2}$. De toda sorte, além de técnicas positivas de adequabilidade diária a se checar como estão protegidos ou ampliados os direitos fundamentais, há ainda a possibilidade de tomar como possível uma porta a dar a este leque uma imprecisão não vista nas regras: o parágrafo $2^{\circ}$ do mesmo Artigo $5^{\circ}$. A amplitude interpretativa poderia se alongar até onde não houvesse segurança, e disto um exercício hermenêutico não pode descuidar. Contudo, não é salutar abandonar à ineficácia um dispositivo constitucional de tal monta, pois o inciso III do Artigo $1^{\circ}$ do mesmo documento nos traz a dignidade da pessoa humana como um dos fundamentos da República. O que seria ela se não a concretização dos direitos humanos? Se certos tratados internacionais sobre direitos humanos ainda não foram recepcionados por qualquer dos modelos apresentados pelo texto constitucional ou ainda por legislação infraconstitucional que o adote, abandonar uma interpretação minimamente ampliativa seria desprezar a própria dignidade da pessoa humana no Ordenamento Jurídico Brasileiro.

Se a dignidade da pessoa humana, vista supra, não guarda limites legais nem doutrinários, pedindo sempre uma nova interpretação frente todo embate que a desafie, mais atual, mais moderna, adequando-se aos novos direitos mínimos que ainda estão por vir, direitos defendidos e necessitados quando de novos modelos e modos de agressões à própria dignidade, os tratados internacionais dos quais tratamos aqui podem nos dar um norte mais concreto. Em verdade, os direitos fundamentais moldam-se, engradecem-se, interagem com novos elementos da ordem jurídica interna e internacional com o principal intuito de velar pelo valor dignidade da pessoa humana. É salutar que as interpretações do texto constitucional e a própria hermenêutica inventiva se encorajem a tomar também como parâmetros disposições desses tratados, tão crus como seus princípios e ontologias, conforme ordena o parágrafo $2^{\circ}$ do Artigo $5^{\circ}$, ou então quedar-se inerte e esperar que sua positivação se dê por linhas mais concretas em regras ou princípios explícitos, seguindo-se para o parágrafo $3^{\circ}$ deste mesmo artigo.

2 O Congresso Nacional aprovou, por meio do Decreto Legislativo $\mathrm{n}^{\circ}$ 186, de 9 de julho de 2008, conforme o procedimento do $\S 3^{\circ}$ do art. $5^{\circ}$ da Constituição, a Convenção sobre os Direitos das Pessoas com Deficiência e seu Protocolo Facultativo, assinados em Nova York, em 30 de março de 2007. 
Por descuido científico, político e legislativo, muito se perdeu, querendo fortalecer temas que já normalmente seriam caros à Constituição Federal e à população brasileira. Se o texto original deste documento consagra que prevalecerão, sempre, os direitos humanos nas relações internacionais das quais a República Federativa do Brasil faça parte, de que serviria uma emenda constitucional e exigir procedimento legislativo bastante mais gravoso para a aceitação desses referidos documentos, os tratados internacionais, que tratem especificamente deste tema?

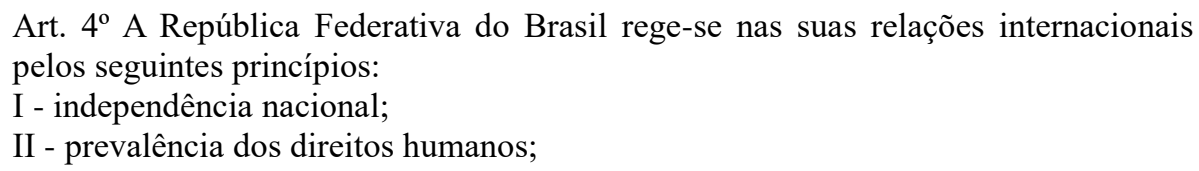

A Emenda Constitucional 45, promulgada em 2004, em verdade, favoreceu os direitos fundamentais? Ela influenciou negativamente de alguma forma uma interatividade dogmático-científica guardada originalmente pela Constituição Federal com o plexo de proteção aos direitos humanos nos dada por tratados internacionais sobre o tema?

\section{DESENVOLVIMENTO}

2.1 O Papel dos Tratados Internacionais sobre Direitos Humanos na Confecção da Norma Jurídica Brasileira

Os tratados a que me refiro neste trabalho carregam um locus político grandioso, capaz de tecer linhas positivas fortes acerca do poder social que instituiu o próprio Ordenamento Jurídico brasileiro. Do povo advém qualquer poder político ou legal presente no Brasil, e para o povo apresenta-se este rol de direitos contra seus pares e contra aqueles que o representam no poder, como limites e como direitos prestacionais verticais e horizontais. Não é outra a interpretação possível do Artigo $1^{\circ}$ da Constituição Federal de $1988^{3}$ :

\footnotetext{
Art. $1^{\mathrm{o}}$ A República Federativa do Brasil, formada pela união indissolúvel dos Estados e Municípios e do Distrito Federal, constitui-se em Estado Democrático de Direito e tem como fundamentos: III - a dignidade da pessoa humana; Parágrafo único. Todo o poder emana do povo, que o exerce por meio de representantes eleitos ou diretamente, nos termos desta Constituição.
}

3 Retirado do sítio de internet http://www.planalto.gov.br/ccivil_03/Constituicao/Constituicao.htm em 28 de Novembro de 2018. 
Os tratados internacionais sobre direitos humanos são objeto de ordem de verificação. Todos eles. A configuração constitucional brasileira ordena que sempre que se argumente uma tese ou uma decisão, se esta lidar direta ou indiretamente com direitos fundamentais, se busque aprofundamentos em documentos de Direito Público Internacional dos quais o Brasil seja parte e que sejam pertinentes ao tema objeto do direito posto em debate. Além disso, técnicas legislativas e hermenêuticas, como o jus cogens e o pro homine, nos fazem alcançar, por sempre, uma valorização de direitos mínimos (o mínimo existencial) quando do estudo e da aplicação do sistema jurídico brasileiro como um todo, tanto por considerar os direitos humanos elementos de consagração da dignidade da pessoa humana, por esse tipo de direito carregar obrigatoriedade quando num embate com outro tipo de direito, como ainda uma interpretação favorável à predominância dos mesmos em embate normativo.

A força interpretativa dos tratados internacionais sobre direitos humanos não se dá por uma mera técnica de interpretação, mas sim por uma força normativa superior que esse tema (direitos humanos) e esses documentos (tratados internacionais) ganharam na Constituição Federal. Num conflito de normas, o pro homine pede que se corrobore e se proteja mais amplamente o direito humano em jogo ou, em embate, aquele mais valioso. Se este valor se der por princípios, objetos do embate se adequarão para ambos existirem. Some-se a isso o fato de a configuração normativa constitucional abrir o Brasil às relações diplomáticas internacionais de uma maneira diferenciada quando estas se derem sobre a proteção da pessoa humana por direitos protetivos.

Não é outro o caminho interpretativo imperativo, de acordo com os parágrafos $2^{\circ}$ e $3^{\circ}$ do Artigo $5^{\circ 4}$ da Constituição Federal de 1988:

\footnotetext{
$\S 2^{\circ}$ Os direitos e garantias expressos nesta Constituição não excluem outros decorrentes do regime e dos princípios por ela adotados, ou dos tratados internacionais em que a República Federativa do Brasil seja parte.

$\S 3^{\circ}$ Os tratados e convenções internacionais sobre direitos humanos que forem aprovados, em cada Casa do Congresso Nacional, em dois turnos, por três quintos dos votos dos respectivos membros, serão equivalentes às emendas constitucionais.
}

O Ordenamento Jurídico Brasileiro pede cientistas em sua interpretação que busquem comandos normativos internacionais a serem tratados como parte de um sistema em busca de adequação. Um documento que se recria para proteger e defender aquilo que motivou sua criação, motivos listados em Ciência do Direito (estudados em áreas como a Sociologia Jurídica), mas que positivamente (o Direito) essa mesma recriação (reinvenção) guarda-se de 
gatilhos legais a facilitar e expandir uma integração necessária, muito para não ver jogada à curadoria de representantes que muitas vezes não se alinham verdadeiramente aos anseios dos representados.

2.2 A Isonomia Constitucional em Cheque Frente ao Avanço das Posições Políticas Brasileiras em Organismos Internacionais de Proteção à Pessoa Humana

A interação do Brasil como República Federativa e pessoa jurídica de Direito Público Internacional em relações bilaterais e multilaterais, principalmente em encontros e órgãos que lidem com direitos humanos de toda ordem, pode produzir crises valorativas e políticas frente aos direitos fundamentais e o quão longe estes poderiam ir no Ordenamento Jurídico interno. Como fruto de atuação política, o Brasil, através do chefe do Executivo Federal agora na atuação de representante de toda a República brasileira, poderá confeccionar e alinhavar outros temas com direitos humanos ainda não listados no rol exemplificativo de direitos fundamentais presentes na Constituição Federal de 1988. E isso poderá levar a uma opção política mais benéfica sobre direitos humanos que aquela positivamente entregue aos cidadãos brasileiros e estrangeiros que vivam no território brasileiro. O presidente da República pode assim proceder:

Art. 84. Compete privativamente ao Presidente da República:

VIII - celebrar tratados, convenções e atos internacionais, sujeitos a referendo do Congresso Nacional $;^{5}$

Esse distanciamento entre o que se entrega internamente, de um lado, e posições, comportamentos, pensamentos e votos em órgãos internacionais dados pela República Federativa do Brasil pode produzir uma interatividade intensa no exercício hermenêutico sobre o rol de direitos fundamentais entregues a aqueles residentes no Brasil por sua Constituição Federal. A isonomia que nos é dada pelo inciso I do Artigo $5^{\circ}$ demandaria, agora, uma leitura mais extensiva?

Art. $5^{\circ}$ Todos são iguais perante a lei, sem distinção de qualquer natureza, garantindo-se aos brasileiros e aos estrangeiros residentes no País a inviolabilidade do direito à vida, à liberdade, à igualdade, à segurança e à propriedade, nos termos seguintes: ${ }^{6}$

5 Idem.

6 Idem. 
A norma da cabeça do Artigo $5^{\circ}$ nos apresenta, além de uma isonomia presente entre aqueles residentes em território nacional, uma possível defesa hígida e legítima de novos direitos comissivos ou omissivos, de caráter fundamental quando o Brasil lidar com direitos humanos em tratados internacionais referendados pelas próprias autoridades brasileiras competentes para tal, abrandando limites presentes a esses direitos no texto constitucional para o âmbito interno, quando confrontados com opiniões ou ações tomadas pelo Brasil quando em atuação em suas relações de Direito Público Internacional? Seria ainda uma barreira legislativa o "novo" procedimento previsto no parágrafo $3^{\circ}$ do Artigo $5^{\circ}$ quando internacionalmente o Brasil defende e aplica de qualquer modo um direito ainda não consagrado positivamente em seu próprio território ou abandona limites de alguns direitos fundamentais listados à Constituição Federal, tornando aquele procedimento, trazido por emenda constitucional, inconstitucional?

Um exemplo de como os limites dos direitos fundamentais em território nacional podem apresentar discrepâncias quando comparados às posições políticas brasileiras em tratados e tratativas internacionais podem ser encontradas quando da adesão brasileira junto ao Tribunal Penal Internacional. O Decreto Legislativo $\mathrm{n}^{\circ} 112^{7}$ do Congresso Nacional, publicado em 26 de Julho de 2001, traz os motivos pelos quais o referido Estatuto de Roma e a adesão do Brasil ao Tribunal Penal Internacional se coadunariam por completo com princípios e regras da República Federativa do Brasil e ainda à Constituição Federal de 5 de outubro de 1988 como um todo. Os itens 10 e 11 do referido decreto não nos deixa dúvidas:

10. A ratificação do Estatuto do TPI estaria em plena sintonia com os princípios da prevalência dos direitos humanos nas relações internacionais e da dignidade da pessoa humana como fundamento do Estado, inscritos na Constituição brasileira. Cabe recordar que a Constituição determina, no artigo $7^{\circ}$ do Ato das Disposições Transitórias, que o Brasil propugnará pela formação de um tribunal internacional dos direitos humanos.

11. A ratificação do Estatuto estaria, além disso, em conformidade com nossa tradição de apoio à cooperação internacional no campo do direito penal e com nossa intenção, tantas vezes reiterada por Vossa Excelência, de contribuir para fortalecer a proteção e a promoção dos direitos humanos tanto no âmbito interno como no plano internacional. No ano passado, o Brasil deu um passo de grande significação nesse sentido ao aceitar a competência contenciosa da Corte Interamericana de Direitos Humanos.

Na República Federativa do Brasil, então, devem os cientistas do Direito render sua hermenêutica constitucional a um leque de dispositivos e documentos que vão além do texto promulgado em 5 de Outubro de 2018, visto que este próprio texto pregou a isonomia de

7 Retirado do sítio de internet http://www2.camara.leg.br/legin/fed/decleg/2002/decretolegislativo-112-6-junho2002-391904-estatuto-1-pl.html em 29 de Novembro de 2018. 
tratamento dentre seus direitos fundamentais, não permitindo que haja favorecimentos ou rigidez em certas áreas entre aqueles posicionados numa mesma linha factual de necessidades e capacidades. Pensar de outro modo nos levaria a infringir esta isonomia.

As mais importantes atividades coordenadas entre países no âmbito internacional são tocadas a se construir uma rede global de direitos que pedem atos comissivos estatais e ainda limites às atividades dos Estados Nacionais, quando se tem em mente esses limites e a defesa e a promoção dos direitos humanos. Entender o Direito Internacional, os mecanismos e artimanhas diplomáticas, que atuam a aproximar países nos mais variados interesses (diplomáticos, políticos lato sensu, bélicos, comerciais, tecnológicos, biológicos, humanitários, etc.) é, necessariamente, entender o rol de Direitos Humanos e sua imposição nos ordenamentos jurídicos internos nacionais. A problemática positivo-filosófico-hierárquica a saber se as regras contidas em documentos internacionais se posicionam com porte objetivo ou como porte subjetivo frente aos ordenamentos jurídicos nacionais, puramente, junta-se à crise valorativa em se entender como proteger a isonomia constitucional brasileira (um direito fundamental) quando, nos tribunais e organismos internacionais dos quais o Brasil faz parte, ele, como pessoa jurídica de Direito Público Internacional, defende novos direitos em âmbitos estrangeiros e, ao mesmo passo, pede atividade legislativa dificultosa como do procedimento das emendas constitucionais para que esses mesmos direitos sejam referendados aos seus cidadãos em seu próprio território. Afinal, de que adiantaria uma emenda constitucional que desburocratizou legislativamente apenas o modelo de proposição para a comunicação de tratados humanos ao rol de direitos fundamentais, mas relega ao tema um procedimento mais rígido de aprovação?

Ministros do Superior Tribunal Federal já observam que os tratados internacionais sobre direitos humanos carregam muito mais que apenas suas regras e a expectativa de procedimentos legislativos para que ganhem normatividade prática junto ao Ordenamento Jurídico Nacional e efetividade junto à população brasileira, principal motivo e foco da atuação política do chefe do Poder Executivo federal no Direito Internacional Público e ainda principal expectador do avançar moroso das atividades legislativas para fazer cumprir o procedimento de emenda. Fachin ${ }^{8}(2018)$ foi um dos que se posicionaram com um olhar mais moderno sobre a temática:

8 Dizeres proferidos pelo Ministro do Supremo Tribunal Federal Luiz Edson Fachin, em palestra junto à Escola da Magistratura do Paraná, em 8 de Junho de 2018, em evento para celebrar os 30 anos da promulgação da Constituição Federal de 1988, que se completaram em 5 de Outubro deste ano. 
O STF tem um encontro marcado (...) para fazer o chamado controle de convencionalidade, a luz do parágrafo $2^{\circ}$ do Artigo $5^{\circ}$ da Constituição. Isso significa, diferentemente do que se tem entendido até o momento (...) eis que este debate está aberto. Isto significa, pelo controle de convencionalidade, que tornar-seá um patamar que entendo mais elevado do que atualmente se admite para os tratados e convenções internacionais, que o Brasil, através de sua jurisdição constitucional, e no controle difuso, portanto isso significa por meio de cada um dos magistrados em todas as comarcas desse país, ou na jurisdição concentrado, por meio do Supremo Tribunal Federal, poderá apreciar uma norma interna, à luz de uma normativa vinculante, de uma convenção ou de um tratado internacional, e que portanto, nessa medida, esse primeiro pilar da Ordem Normativa, nos permite sustentar, como se denomina pela literatura jurídica, um caráter materialmente constitucional dos tratados e convenções internacionais sobre direitos humanos, aos quais o Brasil se vincula. Refiro-me especialmente à Convenção Americana de Direitos Humanos, ao Pacto de Direitos Civis e Políticos, e também à Convenção Interamericana Contra Todas as Formas de Discriminação e Intolerância (...)

Mello 9 (2009) fora outro que atendeu ao papel que os tratados internacionais sobre direitos humanos podem ter no exercício hermenêutico da própria Constituição Federal:

\begin{abstract}
Não se pode desconhecer (...) que se delineia, hoje, uma nova perspectiva no plano do direito internacional. É que, ao contrário dos padrões ortodoxos consagrados pelo direito internacional clássico, os tratados e convenções, presentemente, não mais consideram a pessoa humana como um sujeito estranho ao domínio de atuação dos Estados no plano externo. $O$ eixo de atuação do direito internacional público contemporâneo passou a concentrar-se, também, na dimensão subjetiva da pessoa humana, cuja essencial dignidade veio a ser reconhecida, em sucessivas declarações e pactos internacionais, como valor fundante do ordenamento jurídico sobre o qual repousa o edifício institucional dos Estados nacionais. Torna-se importante destacar, sob tal perspectiva, que a Conferência Mundial sobre Direitos Humanos, realizada em Viena, em 1993, sob os auspícios da Organização das Nações Unidas, representou um passo decisivo no processo de reconhecimento, consolidação e contínua expansão dos direitos básicos da pessoa humana. A Declaração e Programa de Ação de Viena, adotada consensualmente pela Conferência Mundial sobre Direitos Humanos, foi responsável - consoante observa o diplomata brasileiro José Augusto Lindgren Alves (Os direitos humanos como tema global. p. 135/144, item n. 8.2, 1994, Perspectiva) - por significativos avanços conceituais que se projetaram nos planos concernentes à legitimidade das preocupações internacionais com os direitos humanos (art. $4^{\circ}$ ), à interdependência entre democracia, desenvolvimento e direitos humanos (art. $8^{\circ}$ ) e, ainda, ao reconhecimento do sentido de universalidade dos direitos humanos (art. $5^{\circ}$ ). Cumpre não desconhecer, nesse contexto, o alcance e o significado de diversas proclamações constantes da Declaração de Viena, especialmente daquelas que enfatizam o compromisso solene de todos os Estados de promoverem o respeito universal e a observância e proteção de todos os direitos humanos e liberdades fundamentais das pessoas, assegurando-lhes, para esse efeito, meios destinados a viabilizar o acesso à própria jurisdição de organismos internacionais.
\end{abstract}

A isonomia constitucional se porta como mote do tema em debate. Sua força principiológica pode trazer ao embate acerca dos direitos que consagram a dignidade da pessoa humana em território brasileiro balizas não vistas ou, pior, não analisadas pelos órgãos legislativos federais para cumprir ordem explícita da Constituição em integrar-se à

9 RE 466.343, rel. min. Cezar Peluzzo, voto do min. Celso de Mello. Acessado em 28 de Agosto de 2018, através do sítio de internet www.stf.jus.br. 
comunidade internacional, e, mais dramaticamente, ao manto de proteção construído, desenvolvido e protegido por organismos de proteção à pessoa humana quando da confecção de documentos feitos a valorizar e protege direitos humanos de toda ordem.

$$
\text { Ávila }{ }^{10}(\text { fls. 101-102; 2005): }
$$

\footnotetext{
A igualdade pode funcionar como regra, prevendo a proibição de tratamento discriminatório; como princípio, instituindo um estado igualitário como fim a ser promovido; e como postulado, estruturando a aplicação do Direito em função de elementos (critério de diferenciação e finalidade da distinção) e da relação entre eles (congruência do critério em razão do fim). Vale dizer que a aplicação da igualdade depende de um critério diferenciador e de um fim a ser alcançado. Dessa constatação surge uma conclusão, tão importante quanto menosprezada: fins diversos levam à utilização de critérios distintos, pela singela razão de que alguns critérios são adequados à realização de determinados fins; outros, não. Mais do que isso: fins diversos conduzem a medidas diferentes de controle. Há fins e fins no Direito. Como postulado, sua violação reconduz a uma violação de alguma norma jurídica. Os sujeitos devem ser considerados iguais em liberdade, propriedade, dignidade. A violação da igualdade implica a violação a algum princípio fundamental.
}

Assim, a problemática que nos trouxe o parágrafo $3^{\circ}$ do Artigo $5^{\circ}$ da Constituição Federal em 2004 pode ter dificultado em muito uma aproximação lógica e imposta pelos maiores valores presentes no texto original da Constituição Federal de 1988. Regras que poderiam muito bem ser atendidas apenas pelo parágrafo $2^{\circ}$ do Artigo $5^{\circ}$. A crise interpretativa apresentada quando do tratamento sem isonomia dos comportamentos e votos da República Federativa do Brasil junto às relações internacionais de Direito Internacional Público (e, por que não, de Direito Internacional Privado) pode forçar uma releitura de produção normativa que coloque em cheque parte da própria Emenda Constitucional 45, promulgada em 2004, e do parágrafo $3^{\circ}$ adicionado ao Artigo $5^{\circ}$ da Constituição Federal. Sim, todas as emendas constitucionais podem e devem ser analisadas em sua própria constitucionalidade. O Artigo 60 , em seu parágrafo $4^{\circ}$, sobre adequabilidade material das emendas constitucionais:

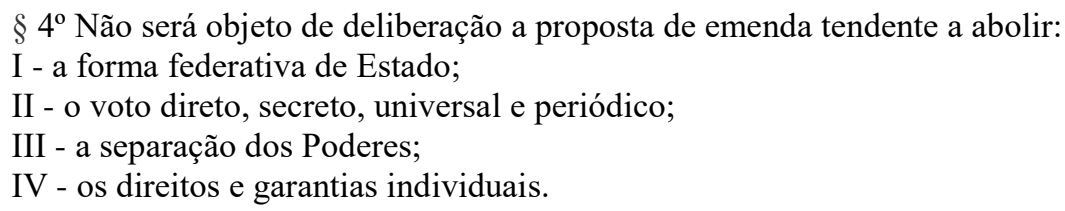

Piovesan ${ }^{11}$ (fl. 93, 2017):

10 ÁVILA, Humberto. Teoria dos Princípios - da definição à aplicação dos princípios jurídicos. 4 edição, revista $-3^{\text {a }}$ triagem. São Paulo-SP: Editora Malheiros Editores, 2005.

11 PIOVESAN, Flávia - Temas de Direitos Humanos Prefácio de Fabio Konder Comparato- 10 ed. revista, ampliada e atualizada - 2017, Ed. Saraiva Jur. São Paulo - SP. 
(...)à medida que guardam relação direta com os instrumentos internacionais de direitos humanos - que lhes atribuem direitos fundamentais imediatamente aplicáveis - os indivíduos passam a ser concebidos como sujeitos de direito internacional. Nessa qualidade, cabe aos indivíduos o acionamento direto de mecanismos internacionais, como é o caso da petição ou comunicação individual, mediante a qual um indivíduo, grupos de indivíduos ou, por vezes, entidades não governamentais podem submeter aos órgãos internacionais competentes denúncia de violação de direito enunciado em tratados internacionais.

Sarlet $^{12}($ fls. 344-345, 2018):

\begin{abstract}
Além disso, a desnecessidade de se recorrer a tal expediente argumentativo, frágil na sua concepção, decorre do fato de que uma hierarquia privilegiada dos tratados de direitos humanos pode ser fundamentada já com base na norma contida no Art. $5^{\circ}$, $\S 2^{\circ}$, da CF, bem como demonstra a doutrina que sustentava, muito antes da inserção do $\S 3^{\circ}$ do Art. $5^{\circ}$, a hierarquia constitucional dos tratados de direitos humanos (doutrina esta que, pelo menos em boa parte, se posiciona de forma bastante crítica em relação ao dispositivo referido).
\end{abstract}

É sempre válido um pensamento a buscar uma harmonia sistemática que se baseie num conjunto alinhado de proposições legais, constitucionais e infraconstitucionais, tendo como meta um bem político e público, delimitado e definido por uma ordem também expressa positivamente por quem detém esse poder político. Assim são os direitos humanos, que foram a carapuça da atividade político-popular que erigiu a Constituição Federal e fê-la defender e promover os direitos fundamentais para consagrar a dignidade da pessoa humana. Se representantes brasileiros se obrigam internacionalmente a respeitar limites de atuação e a consecução de ações positivas perante acordos políticos, permitidos constitucionalmente para tanto, mesmo que não se leve a fio o procedimento delimitado constitucionalmente a tornar essas promessas também objeto de concretização aos brasileiros residentes no Brasil, poderíamos alinhavar outa conclusão que não aquela que exige comportamento isonômico dos que são representantes frente a aqueles que são representados e verdadeiros delegantes do poder dentro do território nacional? Essa linha de construção hermenêutica de uma norma que circunda essas disposições ganha ares dramáticos quando lidamos com direitos humanos por omissão do poder, ou seja, os direitos da liberdade, não-prestacionais.

Servem muito aos exemplos espécies de penas penais, combatidas ou promovidas pelo Brasil internacionalmente quando de um julgamento junto aos tribunais internacionais a que tenha aderido, ou mesmo não aceitas pelo Brasil em posições políticas tomadas em países específicos quando de tratados bilaterais. A extradição passiva brasileira é muito delineada a que se garanta fora dos limites territoriais brasileiros os traços mínimos de dignidade junto às características da pena que se deseja aplicar, por exemplo.

12 SARLET, Ingo Wolfgang; MARINONI, Luiz Guilherme; MITIDIERO, Daniel. Curso de Direito Constitucional. 7 edição. 2018. Saraiva Educação. São Paulo-SP. 


\subsection{A Segurança Jurídica Interpretativa}

Quando lidamos com escolhas, ações, omissões e interpretações, todas de índole constitucional, devemos, sempre, velar pela segurança jurídica. Desta, podemos, portanto, levantar uma chamada segurança interpretativa, produzindo o Direito que se configura em normas e pensamentos, dentro das possibilidades positivas que se arqueiam a alinharem-se com os fatos apresentados para se julgar, controlar, transformando a realidade. Não propomos malabarismos que afastariam uma saudável atividade hermenêutica dos critérios e limites literais, semânticos e sistemáticos do Direito e de nossa Constituição Federal de 1988, mas não podemos abandonar o que constitucionalmente se ordena.

Muitos dos que alegam a grande abertura principiológica a ameaçar uma segurança jurídica do próprio sistema positivo brasileiro, se for dada a dimensão jurídica prática ao que diz a literalidade do parágrafo $2^{\circ}$ do Artigo $5^{\circ}$, não observam que esta intimidade dos sistemas jurídicos externos e internos servem à sobrevivência dos últimos. Em lhe faltando limites interpretativos do que seriam as forças principiológicas, que tomemos o caminho da isonomia constitucional, a pedir comportamentos que consagrem internamente o mesmo que proposto, defendido e praticado internacionalmente pelos representantes brasileiros do povo e chefes dos poderes competentes brasileiros junto às negociações e órgãos de diplomacia quando ditos tratados não forem impugnados interna ou externamente. Se há receio em relegar tão importantes institutos jurídicos como os direitos fundamentais (humanos) aos princípios citados no parágrafo $2^{\circ}$ do Artigo $5^{\circ}$ da Constituição, que tomemos a liberdade de emparelhar-lhes pelo critério isonômico interpretativo a tomar as ações e posições internas e externas do Brasil como sujeito de Direito Internacional Público.

A previsão constitucional está lá, e atacar-se dogmaticamente princípios apenas por estes não apresentarem a certeza e a concretude dadas pelas regras jurídicas positivas não venceria a crise continuada a que nos referimos. Frear a inserção de normas presentes em tratados de direitos humanos, dos quais o Brasil politicamente escolheu participar, por prerrogativa definida originariamente junto à Constituição Federal, não se alinha ao que, primitiva e juridicamente, livremente se acolheu: a valorização da dignidade da pessoa humana e ainda que outros princípios e regimes por este documento adotados por alinhamento dogmático-ontológico possam se juntar ao que se encontra nele escrito. Pedir posteriormente reforma procedimental muito mais dificultosa para que essa congregação de novos temas possa ser concluída, por uma decisão ulterior, escancara uma potencial inconstitucionalidade 
chapada quando da absorção de temas tão relevantes para o povo e, juridicamente, para a Constituição Federal. Direitos fundamentais são, quanto mais primitivos sejam, limites ao poder, prática que define criticamente o que é o republicanismo e a democracia.

Se uma interpretação deve ser razoável e proporcional, assim também os parâmetros e medidas aplicadas e escolhidas pelos representantes políticos brasileiros ao longo de obras e medidas que enfrentem ou promovam direitos humanos quando comparados os quadros internos e internacionais protetivos e promotores de direitos humanos. Um sistema que se fecha interpretativa e documentalmente, antes mesmo de contrariar ordem do próprio texto constitucional, relega-se a reinvenção que lhe faz respirar. Nada mais eficaz, lógico e possível, reverberando valores promotores da dignidade da pessoa humana, que essa prática comece pelos tratados internacionais em defesa dos direitos humanos.

\section{CONSIDERAÇÕES FINAIS}

Os direitos humanos, conforme visto e apontado jurisdicionária, doutrinária e positivamente, guardam um papel que transcende em muito o que seria apenas seu caráter positivo, seja ele manuseado com viés principiológico ou ainda que transformado em regras normativas concretas num caso igualmente real e prático. Essas espécies de direitos, no sistema positivo brasileiro, carregam linhas interpretativas obrigatórias que avançam sobre a suposta liberdade intelectiva num exercício hermenêutico que, agora, deve velar sempre sobre as relações internacionais das quais o Brasil faça parte. Sim, todo cientista jurídico que ouse medir a tenacidade valorativa e positiva de um direito fundamental dentro do Ordenamento Jurídico Brasileiro, sempre numa premissa de supremacia dos direitos fundamentais, deve estar preparado para uma imersão em regras presentes em atividades diplomáticas e políticas de Direito Público Internacional das quais a República Brasileira participe, a buscar novos meandros pelos quais correm novos limites, novos direitos, novas posições e posicionamentos que forcem uma releitura do quadro complexivo de direitos fundamentais, quadro que se soma aos direitos já existentes para moldar, agora e ininterruptamente, o que seria a dignidade da pessoa humana, que se recria, se desenvolve, se reinventa a todo instante. Isto é claro quando, por exemplo, constatamos que o acesso à rede mundial de computadores não era um direito fundamental em 1988, mas que agora ganha este viés. O mesmo se poderia dizer sobre o direito à operação suportada pelo erário público com vistas à alteração de órgãos sexuais. Tudo a prover a dignidade da pessoa humana por novos direitos que se apresentam. Se não 
MAZZUOLI, Valério de Oliveira. Curso de Direito Internacional Púbico. $5^{\mathrm{a}}$ Ed. Rev., Atual. e Ampl. Editora Revista dos Tribunais. 2011 - SP.

PIOVESAN, Flávia. Temas de Direitos Humanos Prefácio de Fabio Konder Comparato10 ed. revista, ampliada e atualizada - 2017, Ed. Saraiva Jur. São Paulo - SP.

RAMOS, André de Carvalho. Curso de Direitos Humanos, 5 ed., Saraiva, 2018.

SARLET, Ingo Wolfgang; MARINONI, Luiz Guilherme; MITIDIERO, Daniel. Curso de Direito Constitucional. 7 edição. 2018. Saraiva Educação. São Paulo-SP.

Sítio de internet do Supremo Tribunal Federal: www.stf.jus.br. Acesso em 1 de Dezembro de 2018.

Sítio de internet da EMAP - Escola da Magistratura do Paraná.

\title{
THE INTERPRETATIVE AND INTEGRATING ROLE OF INTERNATIONAL HUMAN RIGHTS TREATIES BEFORE THE FEDERAL CONSTITUTION
}

\begin{abstract}
The Constituição Federal of 1988 orders, initially and subsequently, by paragraphs 2 and 3 of its Article 5, that principles and rules present in other documents have an important and decisive role in integrating, tacitly changing and still directing interpretations of the constitutional text during concrete handling of the fundamental rights present in the inaugural document of the Brazilian Legal Order System. To understand this order of the constitutional text is to understand the necessary interpretive mechanisms that open the brazilian legal system for the construction of a protective network that is intended to be global and perfect, and which, by legal technique, establishes the position of the holder of brazilian political power: the people. A political integration that is still moving slowly, which objectively produced only a single document, but which could make use principly acts to influence interpretations and concretions of new or stronger rights where the ordinary lawmaker did not proceded to amend the constitutional text itself or, at the very least, to ensure it infraconstitutionally. The brazilian legal system is not limited to new thoughts, rights and international norms when this integration is
\end{abstract}


foreseen, encouraged and ordered, much less when the value lines are already foreseen in the Federal Constitution of October 5, 1988. If not lack legal possibility, we may not be able to say the same about interest, sensitivity and legislative and jurisdictional acumen when dealing with and research on international documents that further color the constitutional gross text.

Keywords: Fundamental Rights. Dignity of Human Person. Treaties. 